\title{
Resenhas
}

CASPARD, Pierre (dir.). La presse d'éducation et d'enseignement, XVIIIe siècle-1940. Répertoire analytique. Paris: INRP. Tome 1: AC, 1981, 560p.; Tome 2: D-J, 1984, 688p.; Tome 3: K-R, 1986, 566p.; Tome 4: S-Z, 1991, 762p.

CASPARD-KARYDIS, Pénélope (dir.).

La presse d'éducation et

d'enseignement. 1941-1990.

Répertoire analytique. Paris: INRP.

Tome 1: A-D, 2000, 764p.; Tome 2: E-K, 2003, 702p.; Tome 3: L-Q, 2005, 402p.; Tome 4: R-Z, 2005, 480p.

\section{A imprensa de educação e de ensino: repertórios analíticos. O exemplo da França.}

Muitas vezes, a pesquisa histórica torna-se difícil e limitada tanto pelo desconhecimento dos documentos disponíveis, como pela inadequada catalogação e conservação. Nesse sentido, um repertório é um importante instru- mento de trabalho para o pesquisador, pois inventaria um determinado tipo de fonte de pesquisa e sinaliza onde encontrá-la. Nessa perspectiva situa-se o repertório produzido pelo Service d'Histoire de l'Éducation (Institut National de Recherche Pédagogique INRP, Centre National de Recherche Scientifique - CNRS et École Normale Supérieur - ENS), onde, durante 25 anos, dois responsáveis e uma dezena de colaboradores contribuíram sucessivamente na sua redação.

O repertório compreende oito volumes, com quase cinco mil páginas, catalogando 3.741 periódicos por ordem alfabética. O primeiro conjunto de quatro volumes, sob a direção de Pierre Caspard e a colaboração de Penélope Caspard-Karydis, André Chambon, Geneviève Fraisse, Denise Poindron, publicado no período de 1981 a 1991, analisa e indexa quase 2.500 revistas, editadas de 1768 (ano de edição do Journal d'Éducation) até 1940. O segundo conjunto de quatro volumes, dirigido por Penélope Caspard-Karydis, publicado entre 2000 e 2005, recenseia mais de 1.200 títulos, que tratam de educação, ensino e formação, no sentido amplo dos termos, editados entre 1941 e 1990. Para os editores, globalmente, o conjunto

reflete as idéias, as proposições, os debates, que estiveram presente na sociedade francesa durante mais de dois séculos, não somente pelos problemas propriamente escolares ou pedagógicos, mas também pelos valores e os conteúdos que julgavam dever transmitir. Mais precisamente, essa imprensa é fundamental para todos aqueles envolvidos na sua produção e circulação; para os vários atores, coletivos ou individuais, para os quais a educação representa uma ação significativa: o Estado, seus administradores e seus agentes; as Igrejas e todos seus dispositivos de ensino e de enquadramento da ju- 
ventude; os partidos políticos; as associações, sindicatos e movimentos de todas as tendências. (CaspardKarydis, 2000, p. 9)

Cada notícia compreende uma descrição bibliográfica e editorial, o objetivo fixado pelo periódico para os seus leitores, uma apresentação dos temas ou assuntos que mais significativamente são abordados no curso de sua história. Contém, ainda, index geográfico, cronológico, das associações e organizações, dos estabelecimentos, onomástico, temático, e a listagem dos periódicos mencionadas nas notícias do repertório. A metodologia adotada para a constituição do repertório consiste na análise do conjunto dos números de cada periódico fichado, para fornecer a descrição bibliográfica, síntese das principais informações materiais sobre ele e a identificação de seus editores, principais responsáveis e redatores (título, subtítulo, anos de existência, órgão editor, filiação com outros periódicos, comitê editor, periodicidade, local de edição e editora); os objetivos, avisos aos leitores e prefácios, que constituem uma "verdadeira antologia do pensamento e da militância educativa" (Caspard-Karydis, 2000, p. 17); os temas abordados, os conteúdos privilegiados; o código de localização na Biblioteca Nacional da França ou em outras bibliotecas parisienses.

O conjunto permite múltiplos campos de pesquisa, que incluem não somente a história da educação, do ensino e da pedagogia, mas também o da cultura, das Igrejas, da família ou da economia. É um significativo instrumento de trabalho, pela diversidade de informações que contém e as inúmeras pistas de reflexão, tanto aos historiadores como aos sociólogos e todos aqueles que se interessam pela educação e seu passado. Também inspirou em outros países a realização de repertórios similares.
A imprensa de educação e de ensino é constituída de periódicos que, destinados em sua maioria aos professores, visam principalmente guiar sua prática cotidiana, oferecendo informações sobre o conteúdo e o espírito dos programas oficiais, a conduta em classe e a didática das disciplinas. Pierre Caspard (1981, p. 8) considera que essa imprensa

\section{[...] constitui um meio indispensá-} vel para o conhecimento do que é o sistema de ensino, o que ele representa, por exemplo, no espaço onde se desenvolve e onde se localizam todos os sistemas, teorias e práticas educacionais, de origem tanto oficial quanto privada. [...] Entre as normas impostas pelo poder central e a prática cotidiana, ao nível de classe, a leitura da imprensa pedagógica permite discernir o que se passa ou não, do centro até a periferia (ou do alto até embaixo), revelando, assim, as reticências ou os boicotes que opõem à instituição escolar as diretrizes que recebe. Inversamente, esta imprensa revela a força de inovação e de proposição que o sistema pode ter encoberto.

Jornais, boletins, revistas, magazines - feitas por professores para professores, feitas para alunos por seus pares ou professores, feitas pelo Estado ou outras instituições como sindicatos, partidos políticos, associações de classe, Igrejas - contêm e oferecem muitas perspectivas para a compreensão da história da educação e do ensino. Sua análise possibilita avaliar a política das organizações, as preocupações sociais, os antagonismos e as filiações ideológicas, além das práticas educativas e escolares.
A imprensa é um corpus documental de vastas dimensões, pois se constitui em um testemunho vivo dos métodos e concepções pedagógicas de uma época e da ideologia moral, política e social de um grupo profissional. É um excelente observatório, uma fotografia da ideologia que preside. Nessa perspectiva, é um guia prático do cotidiano educacional e escolar, permitindo ao pesquisador estudar o pensamento pedagógico de um determinado setor ou de um grupo social a partir da análise do discurso veiculado e da ressonância dos temas debatidos, dentro e fora do universo escolar (Catani \& Bastos, 1997).

Assim, os periódicos constituem uma instância privilegiada para a apreensão dos modos de funcionamento do campo educacional, pois fazem circular informações sobre o trabalho pedagógico, o aperfeiçoamento das práticas docentes, o ensino específico das disciplinas, a organização dos sistemas, as reivindicações da categoria do magistério e outros temas que emergem do espaço profissional. Além disso, acompanhar o aparecimento e o ciclo de vida da imprensa periódica de educação e de ensino permite conhecer as lutas por legitimidade que se travam dentro do campo, e também analisar a participação dos agentes produtores do periódico na organização do sistema de ensino e na elaboração dos discursos que visam instaurar as práticas exemplares. É nesse sentido que se pode afirmar a dupla alternativa que os periódicos pedagógicos oferecem, simultaneamente, como fontes ou núcleos informativos para a compreensão dos discursos, das relações e das práticas, que permitem explicar modalidades de funcionamento do campo educacional (idem).

Para Penélope Caspard-Karydis (2000, p. 20), a imprensa de educação e de ensino "reflete a vida social e associativa desse período histórico, 
sendo um observatório privilegiado de todas as evoluções e todas as revoluções que ocorrem nos conteúdos, nas formas, nos objetivos e nos ideais de educação, de ensino e da formação”. Assim, os eventos que marcaram esse período, como, por exemplo, a Segunda Guerra Mundial e o Maio de 1968, influenciam profundamente a produção dos periódicos. Do total de periódicos inventariados nesse período, mais de 1.200, 182 aparecem antes da Segunda Guerra. Essa guerra, para a autora, “provocou uma desorganização material e humana nas redações das revistas, um espaçamento das publicações, uma perda de assinantes; no entanto, poucos periódicos deixaram de circular definitivamente”. Assinala que, por outro lado, o controle político e a censura foram mínimos, o que possibilitou maior liberdade aos editores, principalmente na zona livre da França.

O grande contingente de publicações, no período da Segunda Guerra e no período imediato ao seu fim, é editado por movimentos ou associações da juventude - laicos ou cristãos. Esses periódicos destinam-se a públicos diferentes, de acordo com a idade, sexo, formação escolar, profissão, com o objetivo de

\section{[...] reconstrução de uma nação nova} sobre valores fortes: tolerância, amizade, auxílio mútuo. Através dessa imprensa, pretendia-se agrupar e enquadrar os jovens, [...] propondo atividades de lazer saudáveis, inculcando valores morais, ao mesmo tempo em que abrir seus horizontes. Assim, a palavra “descoberta” é um tema recorrente: descoberta humana, descoberta dos jovens dos outros países, descoberta científica, descoberta da natureza e do espaço que nos rodeia. (Caspard-Karydis, 2000, p. 11 e p. 17)
Nos anos de 1960, os periódicos testemunham o aumento das revoltas contra a escola, a família, o poder, a autoridade...; o Maio de 1968 é tratado pela maioria das revistas. Esse apoio vai refletir-se nos anos de 1970, quando muitos periódicos adotam uma atitude revolucionária ou provocativa, abordando temas até então tabus “ sexo, drogas, aborto etc.”, falando da má qualidade de vida dos jovens, dos desempregados, da solidão, do suicídio (idem).

Um grupo de periódicos gira em torno do espaço escolar, com o objetivo de ajudar, formar, informar e orientar os pais, estudantes e adultos. Assim, as revistas de educação familiar, destinadas no passado às mães de família, agora se dirigem aos pais. A escolarização e a formação de alunos portadores de deficiências - físicas ou mentais - é outro conjunto significativo de periódicos, que passam a agir em favor da infância inadaptada. Muitos títulos de periódicos também são destinados à formação profissional, em todos os ofícios e com diferentes destinatários: pais, educadores, professores, trabalhadores. Outro conjunto importante de periódicos são as publicações internacionais (por exemplo, da Organização das Nações Unidas para a Educação, a Ciência e a Cultura - UNESCO, da Aliança Francesa etc.), com o objetivo tanto de incentivar a cooperação internacional como de manter contato com o pessoal expatriado, favorecer as trocas pedagógicas, de educação comparada e diversos sistemas educativos.

O estudo do lugar da imprensa pedagógica no discurso social, as estratégias editoriais ante os fenômenos educacionais e sociais revelam-se, assim, ricos de informações ao pesquisador para o resgate do discurso pedagógico, das práticas educacionais, do cotidiano escolar, do grau de submissão dos professores aos programas e às instruções oficiais, da ideologia oficial e do corpo docente, da força de inova- ção e continuidade que representa, das contradições do discurso.

Hoje, no Brasil, com a significativa consolidação dos grupos de pesquisa em história da educação, e com a criação de associações e da Sociedade Brasileira de Pesquisadores em História da Educação, espera-se que esta resenha estimule tanto a organização de um repertório da imprensa de educação e de ensino, a partir do século XIX, por estados da federação, estudos do ciclo de vida de periódicos pedagógicos, isto é, da sua produção, do seu ideário e de sua recepção no meio educacional. Com a ampliação da pesquisa em história da educação, torna-se imprescindível a realização de um estado da arte que analise os estudos que utilizam a imprensa de educação e de ensino como fonte e como objeto de investigação.

\section{Referência bibliográfica}

CATANI, Denice Bárbara; BASTOS, Maria Helena Camara. Apresentação. In: CATANI, Denice Bárbara; BASTOS; Maria Helena Camara (Orgs.). Educação em revista. A imprensa periódica e a história da educação. São Paulo: Escrituras, 1997. p. 5-10.

\section{Maria Helena Camara Bastos} Professora de história da educação Pontifícia Universidade

Católica do Rio Grande do Sul E-mail:mhbastos@pucrs.br 